\title{
Justification of the bridge span vertical stiffness on high-speed railways
}

\author{
Leonid Diachenko ${ }^{1, *}$, and Andrey Benin ${ }^{1}$ \\ ${ }^{1}$ Emperor Alexander I St. Petersburg State Transport University, 190031, Moskovskyi pr. 9, St. Pe- \\ tersburg, Russia
}

\begin{abstract}
When designing bridges on high-speed railways, special attention should be paid to ensuring the safety of train traffic and the comfort of passengers. Excessive structure deformations (both elastic and non-elastic) result in unfavorable irregularities in the train movement pattern on the bridge and so can lead to violation of the traffic safety requirements as well as to vibration and acceleration of the train body, which is inadmissible due to its effect on the human body or the transported goods. In this paper, based on numerical simulation, the results of the study of the motion of a high-speed train along bridge structures of the dynamic bridge- train interaction was performed with respect to various models of high-speed trains running along the bridges. The obtained dependences help to provide a practical assessment of high-speed passenger car dynamics and passenger comfort under the most unfavorable conditions, when the train is running along a multi-span bridge. For these purposes, the dependences of the admissible value of the relative vertical deflection are presented, based on the envelope curves that show the typical dynamic passenger car parameters (natural frequency of car oscillations) and corresponding with their oscillations on the multi-span girder bridges with various lengths
\end{abstract}

\section{Introduction}

Even though the required bearing capacity of the bridge elements is provided, it does not necessarily imply that all terms for its normal operation are observed. Excessive structure deformations (both elastic and non-elastic) result in unfavorable irregularities in the train movement pattern on the bridge and so can lead to violation of the traffic safety requirements as well as to vibration and acceleration of the train body, which is inadmissible due to its effect on the human body or the transported goods [1]. To standardize the bridge span vertical stiffness values means to establish the elastic deformation limits complying with the operational requirements to the bridge structure interacting with the high-speed train. Subsequent paragraphs, however, are indented.

\footnotetext{
*Corresponding author: leonid_dyachenko@mail.ru
} 


\section{Problem statement}

As part of the study, the numerical calculation of the dynamic bridge- train interaction was performed with respect to various models of high-speed trains running along the bridges [27]. In calculations, the train wheels movement patterns were identified as well as the vertical accelerations with-train car bodies.

The most unfavorable and widespread (especially on high-speed lines) case is considered, when the train moves along a multi-span bridge with spans having the same length. The movement patterns of passenger units will consist of tandem irregularities (deflections) caused by the live load stress type.

Thus, as a structural model a chain of spans was taken having the same length of spans (Fig.1) whose value varied in the course of calculation [8].

We introduce the concept of the coach resonant speed equal to the span length - coach vibration frequency product. The speed at which the kinematic effect has a frequency equal to the coach natural frequency [7]:

$$
V_{\text {coach }}^{\text {resonace }}=\frac{f_{c a r} \cdot L}{k}, \text { where } k=1,2,3 \ldots
$$

where $V_{\text {coach }}^{\text {resonance }}$ - coach resonant speed on bridge;

$f_{\text {car }}$ - coach natural vibration frequency;

$L$ - span length.

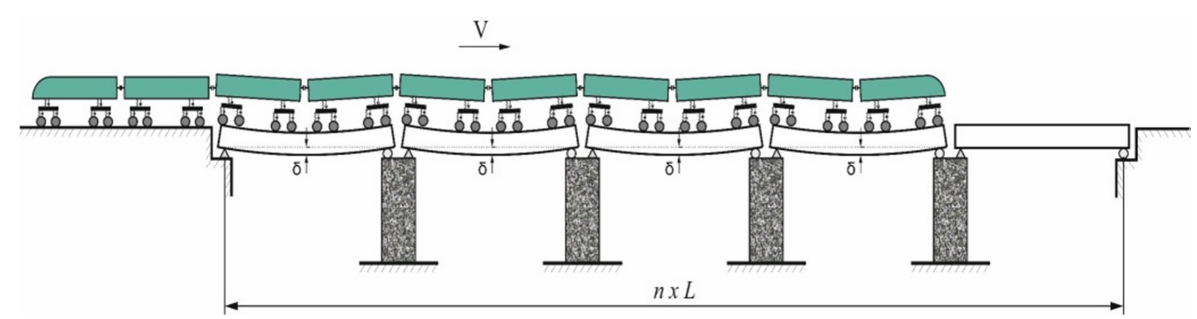

Fig. 1. Model for «bridge-train» dynamic interaction analysis

\section{Analysis of train-bridge dynamic interaction}

From the practical viewpoint, the dependence of the highest railway car vertical acceleration values upon various lengths of the multi-span bridge superstructure is especially interesting. The maximum bouncing accelerations determine the factor of passenger comfort. As far as the admissible vertical accelerations are limited by standard requirements, one can build up a diagram showing the dependence of the vertical deformations of the bridge span (relative deflections) upon various span lengths considered in the passenger comfort test. The kind of this dependence typical of the train moving at a speed of $350 \mathrm{~km} / \mathrm{h}$ is given below. Here and elsewhere in the diagram we show the relative deflections recalculated for the standard load C8 (according to the relevant Russian standards and norms) with respect to the dynamic factor complying with the requirement of limiting the maximum vertical accelerations to the value of $1.0 \mathrm{~m} / \mathrm{sec}^{2}$. The limit value of $1.0 \mathrm{~m} / \mathrm{sec}^{2}$ is selected because the car bouncing is caused not only by the span deflections, but also by track irregularities and wheel defects that lead to accelerations of not more than $0.5 \mathrm{~m} / \mathrm{sec}^{2}$. 


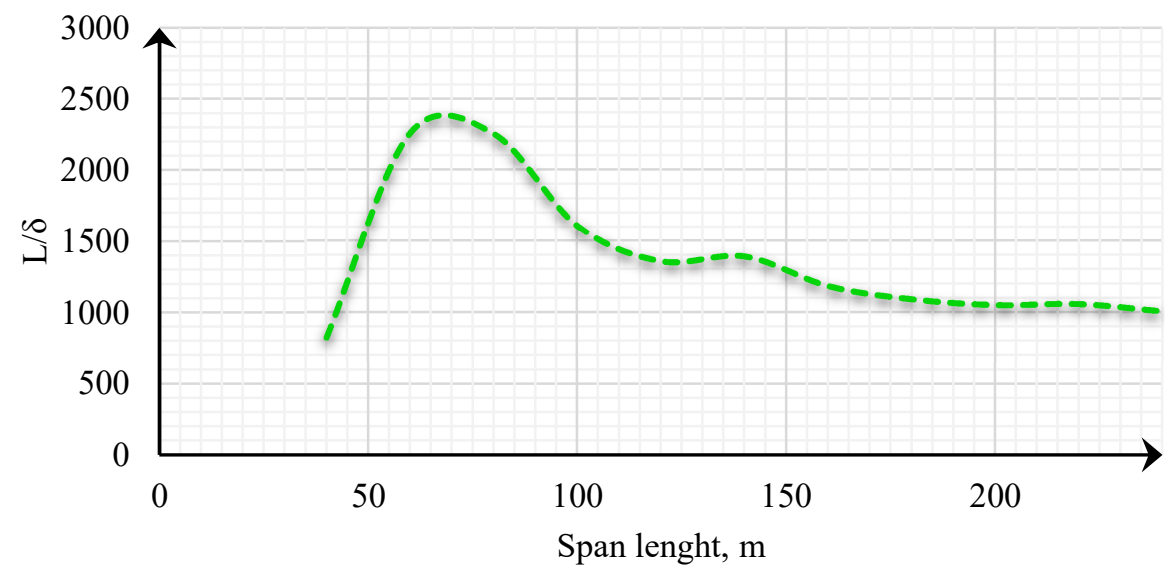

Fig. 2. Dependence of the vertical deformations of the super-structure (relative deflections) upon various span lengths considered in the passenger comfort test

As the frequencies of the natural car body oscillations of the first mode, which are typical of the high-speed trains, have a vast range of values, we have analysed the dependences of the vertical superstructure deflections upon the span lengths with respect to various types of the trains (Table 1, Fig. 3).

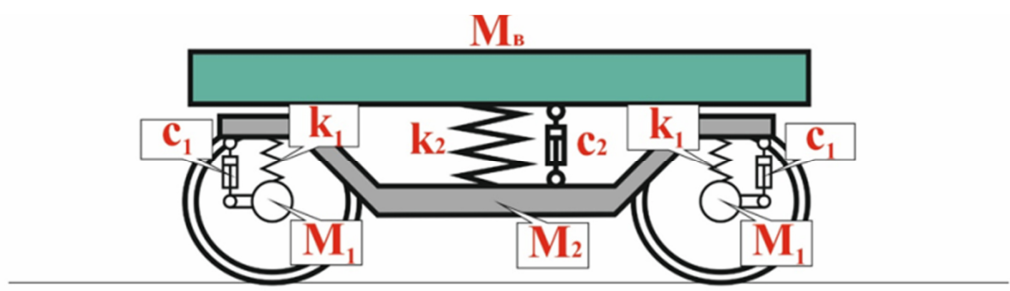

Fig. 3. Model of train car suspension

The given curve comprises clearly defined peaks that correspond with the zones of the car resonant oscillations typical of the relevant span length. In case of different span length values, there are no resonant oscillations in railway cars; moreover, the vertical acceleration values decrease, which helps to raise the value of the relative superstructure deflection. Thus, the highest values of the vertical accelerations in railway cars comply with the conditions of the train-bridge interaction, when the maximum train speed equals to the first critical speed identified against the car resonant oscillations.

Below see the diagram (Fig.4) showing the dependence of the vertical accelerations in the body of the middle car of «Sapsan» train (Velaro RUS) moving at a speed of $350 \mathrm{~km} / \mathrm{h}$ along a chain of ten $120 \mathrm{~m}$ long span (the first resonance). 
Table 1. Parameters of the high-speed trains

\begin{tabular}{|c|c|c|c|c|c|c|c|c|c|c|c|c|c|c|c|c|}
\hline \multirow[b]{2}{*}{ Parameter } & \multirow[b]{2}{*}{ Unit } & \multicolumn{15}{|c|}{ Train model } \\
\hline & & $\begin{array}{l}n \\
2 \\
\sim \\
0 \\
0 \\
0 \\
0 \\
0 \\
0 \\
0 \\
0 \\
0 \\
0 \\
0\end{array}$ & 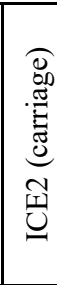 & 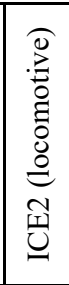 & 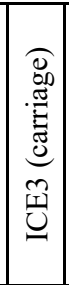 & 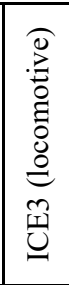 & 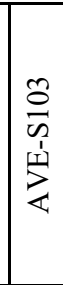 & 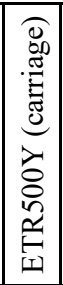 & 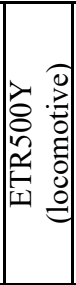 & 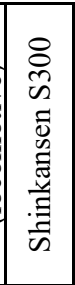 & 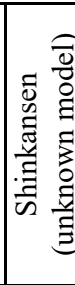 & 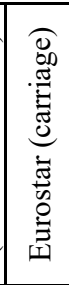 & 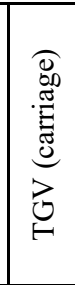 & 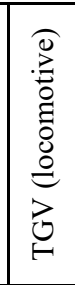 & 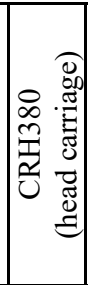 & 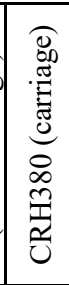 \\
\hline $\begin{array}{c}\text { Mass car } \\
\text { body }\left(\mathrm{MB}^{2}\right)\end{array}$ & $\mathrm{t}$ & 25,4 & 17 & 30,4 & 24,6 & 22,8 & 26,8 & 17,2 & 28 & 20,8 & 20 & 22,6 & 22,6 & 25,8 & 19,4 & 16,8 \\
\hline $\begin{array}{c}\text { Mass of } \\
\text { bogie }\left(\mathrm{M}_{2}\right)\end{array}$ & $\mathrm{t}$ & 4,4 & 2,4 & 5,6 & 2,8 & 4,4 & 3,6 & 2,8 & 3,8 & 3 & 3,3 & 3 & 3 & 2,2 & 3 & 2 \\
\hline $\begin{array}{c}\text { Mass of } \\
\text { wheel }\left(M_{1}\right)\end{array}$ & $\mathrm{t}$ & 1,9 & 1,7 & 2 & 2,4 & 2,4 & 1,8 & 1,6 & 2,1 & 1,8 & 2 & 1,9 & 1,9 & 1,7 & 1,5 & 1,6 \\
\hline \multicolumn{17}{|c|}{ Primary suspension } \\
\hline $\begin{array}{c}\text { Vertical } \\
\text { stiffness }\left(\mathrm{K}_{1}\right)\end{array}$ & $\mathrm{kN} / \mathrm{m}$ & 1900 & 160 & 4800 & 690 & 1120 & 873 & 809 & 1792 & 1180 & 2600 & 2000 & 2000 & 2600 & 1772 & 1772 \\
\hline $\begin{array}{c}\text { Vertical } \\
\text { damping }\left(\mathrm{C}_{1}\right)\end{array}$ & kN.s/m & 31 & 20 & 108 & 5 & 9 & 24 & 8 & 15 & 39 & 80 & 12 & 12 & 120 & 20 & 20 \\
\hline \multicolumn{17}{|c|}{ Secondary suspension } \\
\hline $\begin{array}{c}\text { Vertical } \\
\text { stiffness }\left(\mathrm{K}_{2}\right)\end{array}$ & $\mathrm{kN} / \mathrm{m}$ & 650 & 300 & 1760 & 600 & 560 & 410 & 180 & 472 & 530 & 600 & 580 & 580 & 3260 & 450 & 450 \\
\hline $\begin{array}{c}\text { Vertical } \\
\text { damping }\left(\mathrm{C}_{2}\right)\end{array}$ & kN.s/m & 64 & 6 & 152 & 30 & 28 & 46 & 16 & 36 & 90 & 60 & 20 & 20 & 90 & 20 & 20 \\
\hline
\end{tabular}

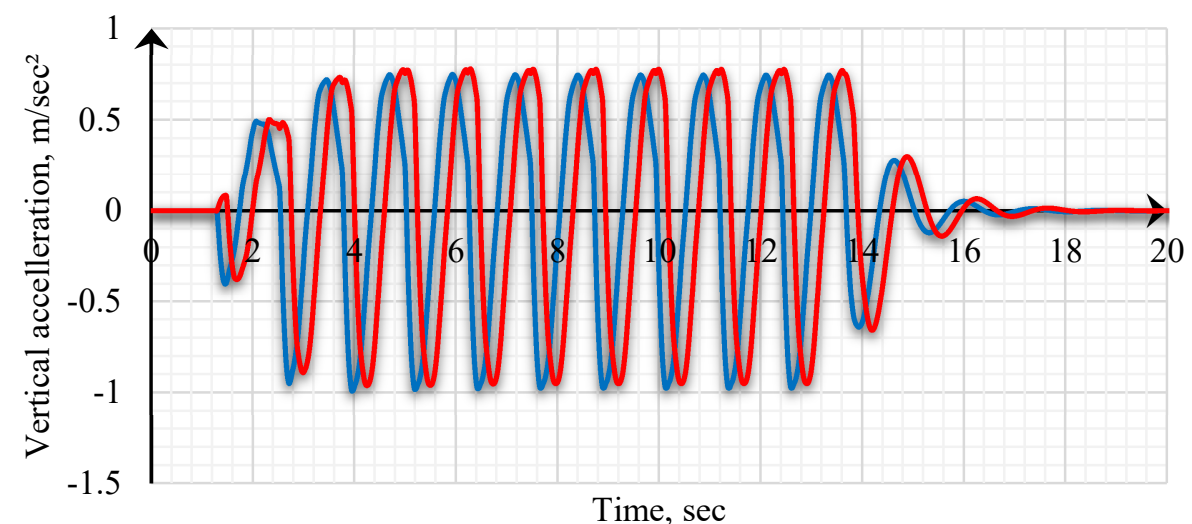

Fig. 4. Vertical accelerations in the body of the middle car of «Sapsan» train (Velaro RUS) moving at a speed of $350 \mathrm{~km} / \mathrm{h}$

Because of kinematic impact, one can observe a resonant increase in amplitudes of vertical accelerations when passing a series of irregularities (superstructures deformed by live load); this increase may be up to the value of $1.0 \mathrm{~m} / \mathrm{sec} 2$ - the one being the limit value. Once the cars have left the structure, the bouncing shortly fades away.

It should be noted that the cars placed in the middle of the train follow a symmetrically bended curve corresponding with the deformed superstructure profile, whereas the first car 
and the last car have an asymmetrical movement pattern against the middle of the superstructure, which is definitely the reason why the bouncing amplitudes increase.

Identifying the type of the bridge-train interaction and analysing their common oscillations, we have defined the linear dependence of the maxi-mum vertical accelerations in the car body upon the train speed. Based on this as well as on a series of calculations, envelope curves characterizing the dependences of the relative superstructure deflection upon various span lengths were devised; these dependences will serve as a foundation for the passenger comfort test $[9,10]$.

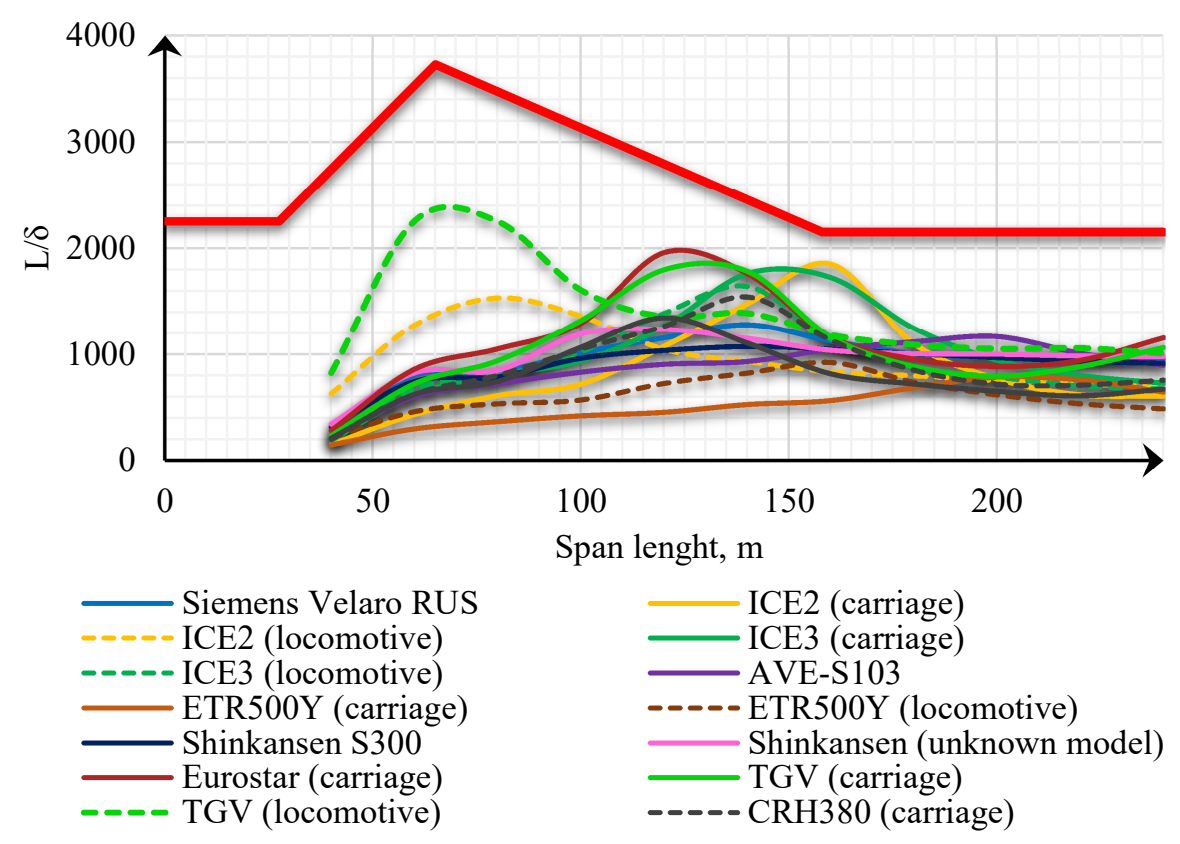

Fig. 5. Limitation of the span vertical elastic deflections aimed to provide maximum accelerations in car bodies of $1.0 \mathrm{~m} / \mathrm{s}^{2}$ for different train types (speed up to $350 \mathrm{~km} / \mathrm{h}$ )

On the presented diagram (Fig. 5) one can see that the dependences of the relative vertical span deflection on the different span length for the calculation for various types of real trains fit into the regulatory requirements.

It should be noted that for the majority of trains with distributed load, the comfort condition of passengers is carried out with a large margin. These trains, as a rule, have a "soft" suspension and small values of the natural frequencies of oscillations of the car body. For trains with a locomotive load (for example, TGV), the suspension is more rigid and the requirements for limiting vertical deflections of span structures are higher.

\section{Conclusion}

The obtained dependences help to provide a practical assessment of high-speed passenger car dynamics and passenger comfort under the most unfavourable conditions, when the train is running along a multi-span bridge. For these purposes, the dependences of the admissible value of the relative vertical deflection are presented, based on the envelope curves that show the typical dynamic passenger car parameters (natural frequency of car oscillations) and corresponding with their oscillations on the multi-span girder bridges with various lengths. 
The difference of the given recommendations from the similar requirements of European Norms is the fact that the curve is not limited to the span length of $120 \mathrm{~m}$, which lets to assess the long-span structure against the passenger comfort factor without making complicated dynamic calculations with respect to the train-bridge interaction. Unlike European Norms [12], the suggested limits describe both fundamental and multiple resonance modes of car oscillations on the superstructure. The described dependences are associated with the Russian standard [11] live load CK $(K=8)$ rather than the European LM71.

\section{References}

1. L. Diachenko, V. Smirnov, E. Dudkin, Proceedings of St. Petersburg State Transport University 14(1), 33-42 (2017)

2. G. M. S. Neves, A. Azevedo, R. Calçada, Conference: IABMAS 2008 (Seoul, Korea 2008), DOI: 10.1201/9781439828434.ch79

3. R. Delgado, SM. Santos. Computers \& Structures; 63, 511-523 (1997) DOI:10.1016/S0045-7949(96)00360-4

4. N. Zhang, H. Xia, W. Guo, Journal of Sound and Vibration, 309(3-5), P. 407-425 (2008)

5. Y. B.Yang, J. D. Yau, Y. S. Wu, Vehicle-Bridge Interaction Dynamics: With Applications To High-Speed Railways. Singapore: World Scientific Publishing Company (2004)

6. S. G. M. Neves, P. Aires Montenegro, A.F.M. Azevedo, R. Calçada, Conference: The Second International Conference on Railway Technology: Research, Development and Maintenance (Ajaccio, Corsica 2014) DOI: 10.4203/ccp.104.81

7. L. Dyachenko, A. Benin, MATEC Web of Conferences, 00014 (2017) DOI: 10.1051/matecconf/201710700014

8. L. Diachenko, A. Benin, V. Smirnov, A. Diachenko, Civil and Environmental Engineering 14(1). 37-43 (2018) DOI: 10.2478/cee-2018-0005

9. L. Dyachenko, A. Benin, A. Dyachenko, MATEC Web of Conferences Siberian Transport Forum - TransSiberia 2018 (2018) DOI: 10.1051/matecconf/201823905002

10. L. Dyachenko, A. Benin, A. Dyachenko, IOP Conf. Series: Materials Science and Engineering 463 (2018) 022048 DOI: 10.1088/1757-899X/463/2/022048

11. V. Zubkov, A. Lukin, V. Alpatov, MATEC Web of Conferences 196, 01005 (2018). DOI: $10.1051 /$ matecconf/201819601005

12. W. Strielkowski, E. Volkova, L. Pushkareva, D. Streimikiene, Energies 12(7), 1392, (2019). DOI: $10.3390 /$ en12071392 